\title{
Schneller, weiter, nachhaltiger
}

Liebe Leserin, lieber Leser,

in Sachen Elektromobilität war das Urteil von Presse und Öffentlichkeit für VW, Mercedes und BMW in Deutschland in letzter Zeit gern wahlweise „,zu dröge“ oder „zu lahm“, sprich einfach rückständig im Vergleich mit dem unbestreitbar innovativen Vorreiter Tesla. Es erinnerte an die 90er-Serie „Die Dinos“ mit einer lapidaren verbalen Keule à la Baby Sinclair: „nicht der Tesla“ - ergo alles doof. Mit Dieselgate hatte sich das noch verstärkt; enttäuschte Liebe neigt bekanntlich dazu, nachtragend zu sein.

Das Bild im Ausland ist ein anderes: Geformtes Blech mit deutscher Ingenieurskunst unter der Haube unterliegt dort bislang einer geringeren Inflation in Sachen Ruf. Auch tun BMW, Mercedes und insbesondere VW momentan einiges, um den Punkt „nicht der Tesla“ auszubügeln. In Bezug auf die Elektromobilität scheint der Schalter umgelegt: McKinsey schätzt, dass die genannten Unternehmen bereits 2021 mehr Elektrofahrzeuge produzieren werden als alle chinesischen Hersteller zusammen. Dank der wachsenden Stückzahlen könnte so ganz nebenbei auch Teslas Geschäftsmodell des Zertifikatverkaufs an die Konkurrenz (2020 rund 1,6 Milliarden US-Dollar) nach und nach der Stecker gezogen werden. Wie der Amerikaner sagen würde: They gain momentum.

Hilfreich für den Wettbewerb um die Marktführerschaft dürfte es sein, eine breite Modellpalette bis ins untere Preissegment in guter Qualität zu produzieren. Und ein weiterer Punkt wird sein, dass man den Weg konsequent bis zum Ende geht und die Fahrzeuge möglichst nachhaltig konzipiert und baut. Wie das mithilfe vieler Teilprojekte gehen kann, zeigten Unternehmen aus der Branche beim diesjährigen Sustainability Award in Automotive 2021 - mehr dazu auf Seite 70. Dabei gibt das Thema Nachhaltigkeit eine wegweisende Chance zur Differenzierung: Damit die Geschichte mit der Elektromobilität insgesamt rund wird, muss eine Gesamtbetrachtung der Bereiche Antriebstechnik, Gesamtfahrzeug und Operations \& Supply Chain im Verein mit einer Energieversorgung her, die sich Richtung $\mathrm{CO}_{2}$-Neutralität bewegt. Sonst macht das saubere Elektroauto an $(\mathrm{zu})$ vielen Stellen nichts anders als der Verbrenner - nur woanders. Wer es hinbekommt, das von der Wiege zur Bahre umweltfreundlichste Fahrzeug auf die Straße zu bringen, könnte davon letztlich profitieren - jenseits der Frage, ob (B)EV only und ob oder wann die Wärmekraftmaschine das Schicksal der Dinosaurier teilen wird.

Viel Spaß bei der Lektüre des Hefts.

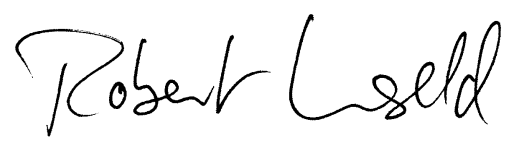

Robert Unseld

Verantwortlicher Redakteur

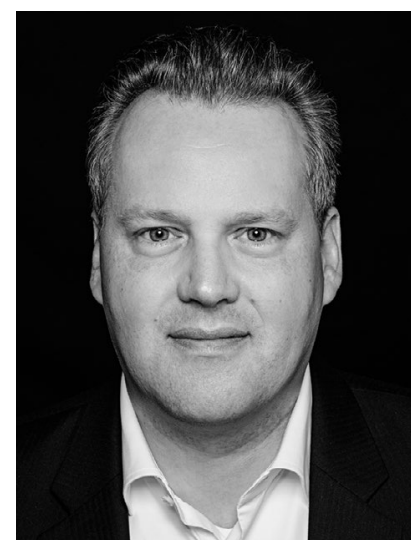

SCS ${ }^{\circledR}$ SMART CONTROL SYSTEMS Intelligentes Schalten, Schützen, Überwachen mit CAN



Unsere Antwort auf Digitalisierung und steigende Komplexität: CAN-fähige Stromverteiler und I/O-Module.
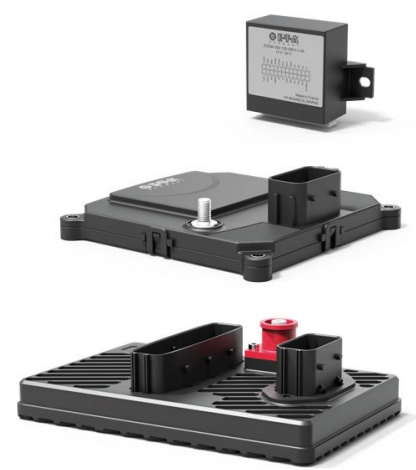

CAN J1939

Ihr Nutzen:

- Condition Monitoring durch Diagnosefähigkeiten (Strom, Spannung, Lastschutz)

- Vernetzung und Datenübertragung durch den CAN 2.0B-Standard und J1939-Kompatibilität

- Kosteneinsparung durch Reduktion des Verdrahtungsaufwands

- Hohe IP Schutzklassen bis IP67

- Bis zu 280 A in kompakter Bauform

Für mehr Infos
bitte QR-Code scannen! 